Research Article

\title{
Estimation of Rotor Temperature of Permanent Magnet Synchronous Motor Based on Model Reference Fuzzy Adaptive Control
}

\author{
Hongchang Ding $\mathbb{D}^{\mathbb{D}}$, Xiaobin Gong, and Yuchun Gong \\ College of Mechanical and Electronic Engineering, Shandong University of Science and Technology, Qingdao, China \\ Correspondence should be addressed to Hongchang Ding; dhchang@sdust.edu.cn
}

Received 17 January 2020; Revised 9 March 2020; Accepted 19 March 2020; Published 29 April 2020

Academic Editor: Ning Sun

Copyright (c) 2020 Hongchang Ding et al. This is an open access article distributed under the Creative Commons Attribution License, which permits unrestricted use, distribution, and reproduction in any medium, provided the original work is properly cited.

\begin{abstract}
For high-speed permanent magnet synchronous motor (PMSM), its efficiency is significantly affected by the performance of permanent magnets (PMs), and the phenomenon of demagnetization will occur with the increase of PM temperature. So, the temperature detection of PMs in rotor is very necessary for the safe operation of PMSM, and direct detection is difficult due to the rotation of rotor. Based on the relationship between permanent magnet flux linkage and its temperature, in this paper, a new temperature estimation method using model reference fuzzy adaptive control (MRFAC) is proposed to estimate PM temperature. In this method, the model reference adaptive system (MRAS) is built to estimate the permanent magnet flux linkage, and the fuzzy control method is introduced into MRAS, which is used to improve the accuracy and applicable speed range of parameters estimated by MRAS. Different permanent magnet flux linkages are estimated in MRFAC based on the variation of stator resistance, which corresponds to different working temperatures measured by thermal resistance, and the PM temperature will be obtained according to the estimated permanent magnet flux linkage. At last, the back electromotive force (BEMF) is measured on the experimental motor, and the flux linkage and PM temperature of the experimental motor are deduced according to the BEMF. Compared with the experimental results, the estimated PM temperature is very close to the actual test value, and the error is less than $5 \%$, which verifies that the proposed method is suitable for the estimation of PM temperature.
\end{abstract}

\section{Introduction}

High-speed permanent magnet synchronous motor (PMSM) has many advantages such as high rotating speed, small volume, high efficiency, high power, and high torque density, and it has been widely used in many industrial fields. Since the excitation magnetic field is provided by permanent magnet, the performance of PMSM is highly dependent on the permanent magnet (PM) temperature; irreversible demagnetization will occur when the PM temperature rises to a certain value $[1,2]$. Therefore, it is important to detect the temperature of PMs in rotor to prevent the performance degradation of PMSM.

Methods for detecting PM temperature are mainly divided into two types: direct detection method and indirect estimation method $[3,4]$. The direct detection method needs to install temperature sensors into the motor, and the sensors include contact sensors such as thermistors or thermocouples and noncontact sensors like infrared sensors $[5,6]$. The advantage of the direct detection method is that temperature data are easily obtained, and the obtained data have small error. On the other hand, the direct detection method requires temperature sensors and extra complicated data transmission device [7-10], which will increase the total cost of system and reduce the robustness of control system of PMSM.

Another method is to estimate the PM temperature according to the parameters relating to temperature. Through consulting different literatures, there are three main methods for estimating the PM temperature, including thermal model, high-frequency signal injection, and back electromotive force (BEMF) $[4,5,7,11,12]$. The thermal 
model includes the finite element model (FEM) and lumped parameter model (LPM), which can provide very detailed temperature distribution of PMSM. But this method requires precise knowledge of the machine geometry, materials, and cooling system [13-15]. Furthermore, the temperature has impact on the properties of the materials, just like winding resistance, magnet remanence, and intrinsic coercivity, and the model needs to be appropriately adjusted for different motors. The high-frequency signal injection method is based on the variation of high frequency resistance with temperature, which can be measured by the feedback current after injecting high-frequency voltage. This method can be used to estimate the temperature at low speed, including zero speed [5,7], but it will have adverse effects on the machine, such as unnecessary mechanical vibration. Based on the linear relationship between the PM temperature and flux linkage, the BEMF method is proposed to estimate the PM temperature according to the calculated value of flux linkage $[4,16,17]$, but the establishment of the model of flux observer is more complicated, and it needs to eliminate fundamental components of the obtained BEMF and make complex analysis of harmonic components, and it cannot estimate the PM temperature when machine operates at standstill or low speed.

For PMSM, parameters such as rotor position and speed are necessary information for motor control, but the usage of position or speed sensor will reduce the robust performance of the motor, so different sensorless control methods of PMSM have been presented and studied for decades [18]. The model reference adaptive system (MRAS) method is one of the widely used algorithms to estimate the real-time parameters of the motor $[19,20]$, which has the advantages of less calculation, good anti-interference performance, easy convergence, and high steady-state accuracy, etc. In addition, nonlinear control of underactuated systems [21] and the convergence of the closed-loop system [22] are all helpful for the sensorless control of PMSM.

Based on the relationship between permanent magnet flux linkage and its temperature, the MRAS method can be used to estimate PM temperature according to the permanent magnet flux linkage. However, this method needs to establish an accurate mathematical model, and the model must be a linear stationary system. On the other hand, the fuzzy control algorithm does not require accurate mathematical model, and it has high accuracy, good parameter tracking performance, and good control performance $[23,24]$, which has a good complementary effect for MRAS.

In this paper, a new temperature estimation method using model reference fuzzy adaptive control (MRFAC) is proposed to estimate PM temperature. In this method, the model reference adaptive system (MRAS) is built to estimate the permanent magnet flux linkage, and the fuzzy control method is introduced into MRAS, which is used to improve the accuracy and applicable speed range of parameters estimated by MRAS. Different permanent magnet flux linkages are estimated in MRFAC based on the variation of stator resistance, which corresponds to different working temperatures measured by thermal resistance, and the PM temperature will be obtained according to the estimated permanent magnet flux linkage. The main contributions of this paper are listed as follows:

Due to the limitations of traditional temperature measurement methods of PM temperature in rotor of PMSM, a new temperature estimation method is proposed to estimate the PM temperature according to the permanent magnet flux linkage. This method combines the advantage of MRAS and fuzzy control, and it can obtain the PM temperature in rotor under different stator temperature conditions, which expands the traditional indirect temperature detection methods.

Different from the usage of fuzzy algorithm in the traditional MRFAC method,in this paper, $d$-axis current error $\left(e_{d}\right)$ is fuzzed before it enters into the adaptive mechanism in the inductance estimation model (Figure 1); for the flux linkage estimation model, the fuzzy control algorithm is used to replace the adaptive mechanism (Figure 2). The changed usage of fuzzy control algorithm improves the estimation performance and applicable speed range of estimated parameters.

The back electromotive force (BEMF) is measured on the experimental motor, and the flux linkage and PM temperature of experimental motor are deduced according to the BEMF. Compared with the experimental results, the estimated PM temperature is very close to the actual test value, and the error is less than $5 \%$, which verifies that the proposed method is suitable for the estimation of PM temperature.

This paper is organized as follows. Firstly, the calculation principle of PM temperature through flux linkage is presented. Secondly, the estimation method based on MRFAC is designed. Then, the stator winding resistances are calculated according to the measured temperature, and the values of stator inductance and permanent magnet flux linkage are estimated. Finally, experiments are designed to verify the accuracy of the estimation value of the proposed method. The flowchart of PM temperature estimation is shown in Figure 3.

\section{Principle of the BEMF-Based Method}

As the proposed method to estimate PM temperature is based on MRFAC, in which the inductance and flux linkage are estimated, the PM temperature is indirectly calculated by the same principle as BEMF-based method. Here, the BEMF-based method for estimating PM temperature is outlined for reader's convenience.

The fundamental model of a PMSM in the rotor reference frame is described as [25]

$$
\begin{aligned}
& V_{d}=R i_{d}+p L_{d} i_{d}-\omega L_{q} i_{q}, \\
& V_{q}=R i_{q}+p L_{q} i_{q}+\omega\left(L_{d} i_{d}+\lambda_{m}\right),
\end{aligned}
$$

where $V_{d}$ and $V_{q}$ are $d$-axis and $q$-axis voltages, respectively, $i_{d}$ and $i_{q}$ are $d$-axis and $q$-axis currents, $p$ is differential operator, $L_{d}$ and $L_{q}$ are $d$-axis and $q$-axis stator inductance, $R$ is stator resistance, $\omega$ is electrical rotor angular speed, and $\lambda_{m}$ denotes flux linkage. 


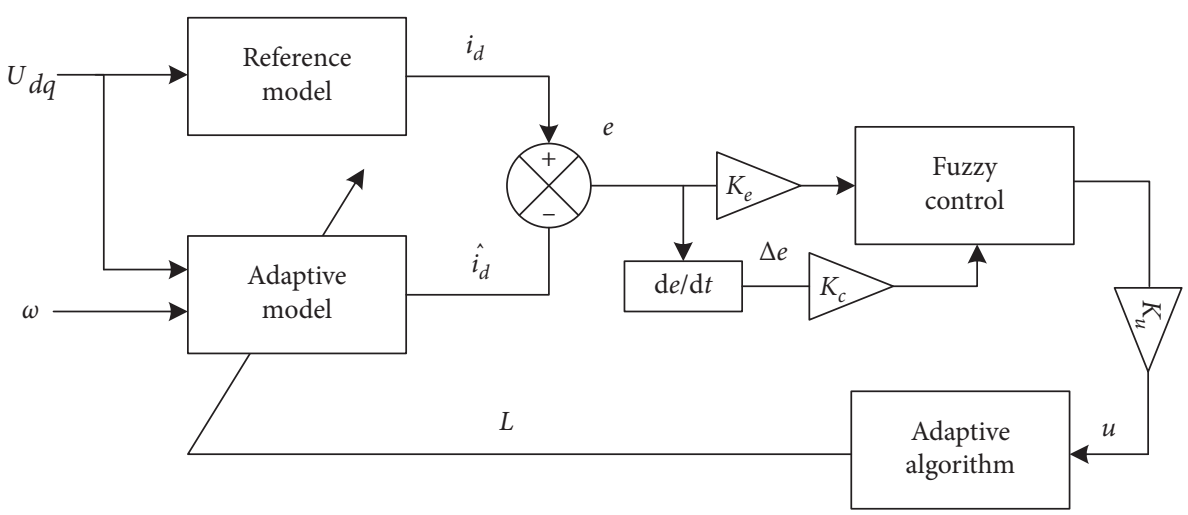

FIgURE 1: Simulation model of MRFAC.

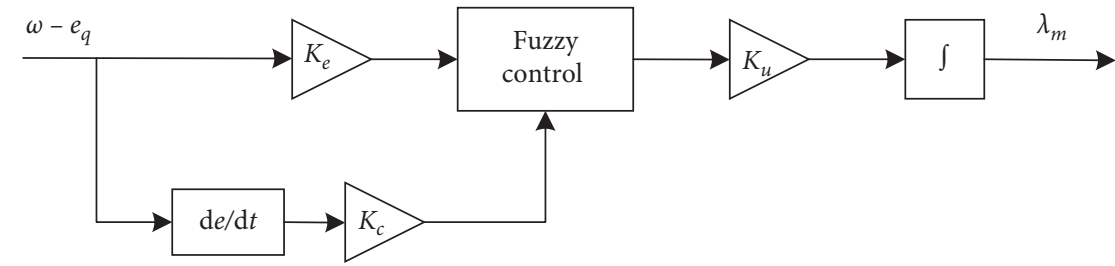

Figure 2: Adaptive mechanism of fuzzy control.

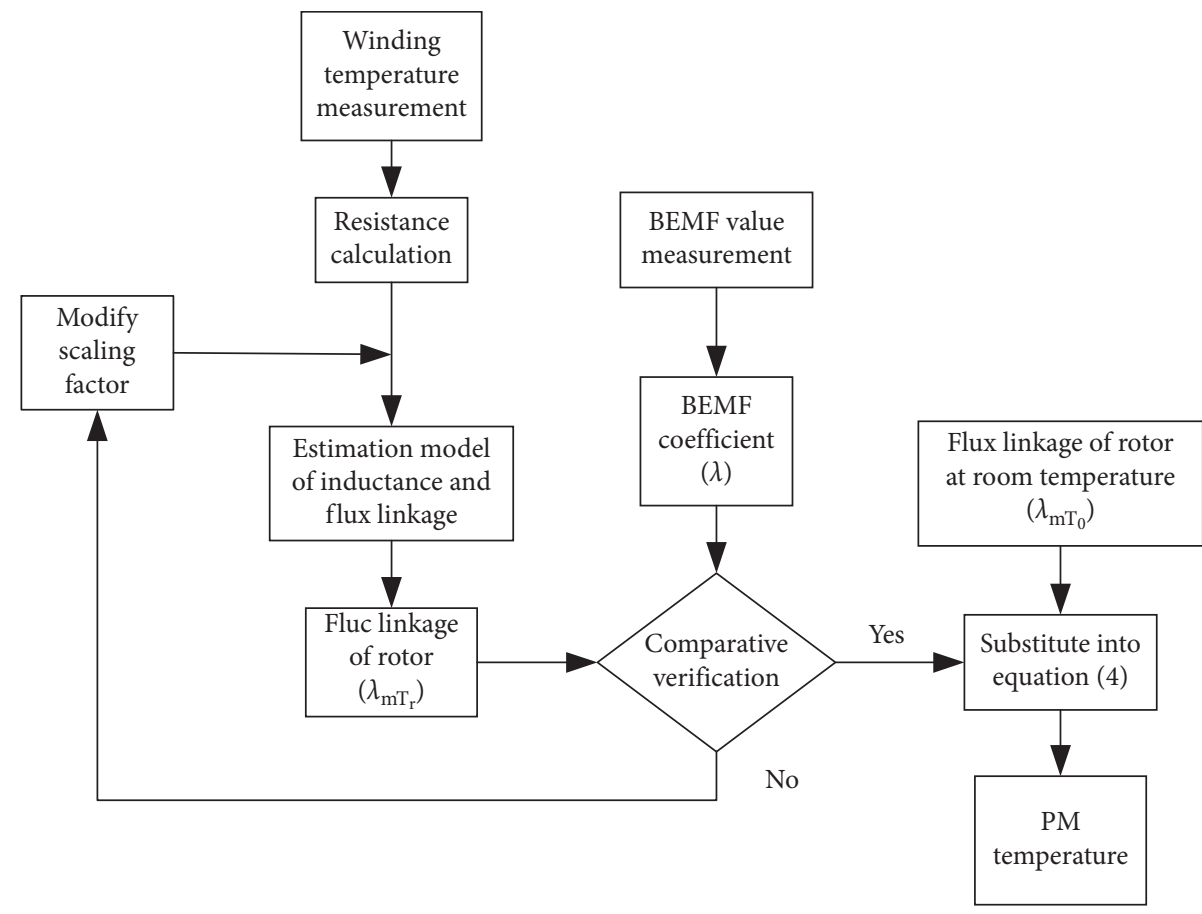

FIgURE 3: Flowchart of PM temperature estimation.

Because $\lambda_{m}$ only exists in the $q$-axis equation, the voltage equation of $q$-axis can be written as follows:

$$
\lambda_{m}=\frac{V_{q}-\left(R i_{q}+p L_{q} i_{q}+\omega L_{d} i_{d}\right)}{\omega} .
$$

The linear relationship between flux linkage and PM temperature can be expressed as

$$
\lambda_{m\left(T_{r}\right)}=\lambda_{m\left(T_{0}\right)}\left[1+\beta\left(T_{r}-T_{0}\right)\right],
$$

where $T_{r}$ and $T_{0}$ are the rotor temperature and room temperature, respectively, $\lambda_{m\left(T_{0}\right)}$ and $\lambda_{m\left(T_{r}\right)}$ are flux linkage at room temperature and actual rotor temperature, and $\beta$ is the magnet flux thermal coefficient. The PM temperature in rotor can be expressed as follows: 


$$
T_{r}=\frac{1}{\beta}\left[\frac{\lambda_{m\left(T_{r}\right)}}{\lambda_{m\left(T_{0}\right)}}-1\right] .
$$

The relationship between the winding resistance and winding temperature can be expressed as follows [12]:

$$
R=R_{0}\left[1+\alpha\left(T_{2}-T_{0}\right)\right],
$$

where the value of the winding resistance is linear with the temperature, $\alpha$ is the temperature coefficient of stator winding, $T_{2}$ and $T_{0}$ are actual winding temperature and room temperature, and $R$ and $R_{0}$ represent the winding resistance value at $T_{2}$ and $T_{0}$, respectively.

\section{Estimation of Parameters Based on MRAS}

3.1. Estimation of Stator Inductance. In equations (1) and (2), the resistance value is measured under different stator winding temperatures, and currents and voltages are also measured. Beyond that, there are two unknown parameters: $L$ and $\lambda_{m}$. As the motor model is a surface-mounted PMSM, the inductances of $d$-axis and $q$-axis are equal, which will simplify the following analysis work.

The first estimated parameter is the stator inductance; for better observation of the estimated parameter, equation (1) can be rewritten as follows [26]:

$$
\frac{\mathrm{d} i_{d}}{\mathrm{~d} t}=-\frac{R}{L} i_{d}+\omega i_{q}+\frac{V_{d}}{L}
$$

where $R$ is a known value, $\omega, i_{d}$, and $i_{q}$ need to be measured. Here, the estimated parameter equation can be obtained according to equation (7), and the superscript symbol represents the estimated value in equation (8).

$$
\frac{\mathrm{d} \hat{i_{d}}}{\mathrm{~d} t}=-\frac{R}{L} \hat{i_{d}}+\omega i_{q}+\frac{V_{d}}{L} .
$$

Subtracting equation (8) from equation (7), the error equation is obtained as

$$
\frac{\mathrm{d} e_{d}}{\mathrm{~d} t}=-\frac{R}{L} e_{d}-\triangle \frac{1}{L}\left(V_{d}-R i_{d}\right)=A e_{d}-W,
$$

where $e_{d}$ and $\Delta(1 / L)$ denote the difference of $d$-axis current and inductance between the reference model and the adaptive model, respectively, $e_{d}=i_{d}-\hat{i_{d}}$, and $\Delta(1 / L)=$ $(1 / \hat{L})-(1 / L)$.

In order to guarantee the stabilization of the estimation method, Popov's super stability theory is adopted, and the adaptive law is derived by using Popov's integral inequality:

$$
\int_{0}^{t_{1}} e^{T} W \mathrm{~d} t \gg-\gamma^{2}
$$

where $\gamma$ is a limited positive constant.

By solving the Popov inequality, the inductance $L$ can be estimated as follows:

$$
\frac{1}{\hat{L}}=\frac{1}{\hat{L}}(0)+\left(k_{p}+\frac{k_{i}}{s}\right)\left[e_{d}\left(V_{d}-R \hat{i_{d}}\right)\right],
$$

where $k_{p}$ and $k_{i}$ are proportionality coefficient and integral coefficient.

3.2. Estimation of Flux Linkage. To estimate the flux linkage, equation (2) can be rewritten as

$$
\frac{\mathrm{d} i_{q}}{\mathrm{~d} t}=-\frac{R}{L} i_{q}-\omega i_{d}+\frac{V_{q}}{L}-\omega \frac{\lambda_{m}}{L},
$$

where $\lambda_{m}$ is the unknown value, $\omega$, and $V_{q}$ are measured parameters. The estimated value of $i_{q}$ and $\lambda_{m}$ can be expressed as follows:

$$
\frac{\mathrm{d} \hat{i_{q}}}{\mathrm{~d} t}=-\frac{R}{L} \hat{i_{q}}-\omega \hat{i}_{d}+\frac{V_{d}}{L}-\omega \frac{\hat{\lambda_{m}}}{L} .
$$

Subtracting equation (13) from equation (12), equation (14) is obtained.

$$
\frac{\mathrm{d} e_{q}}{\mathrm{~d} t}=-\frac{R}{L} e_{q}-\frac{\omega}{L} \Delta \lambda_{m}=A e_{q}-W,
$$

where $e_{q}$ and $\Delta \lambda_{m}$ denote the difference of $q$-axis current and flux linkage between the reference model and the adaptive model, respectively, $e_{q}=i_{q}-\hat{i}_{q}$, and $\Delta \lambda_{m}=\lambda_{m}-\lambda_{m}$.

In order to satisfy Popov's integral inequality, the adaptive rule of $\lambda_{m}$ is established as follows:

$$
\hat{\lambda_{m}}=\hat{\lambda_{m}}(0)-\left(k_{p}+\frac{k_{i}}{s}\right)\left(\omega \cdot e_{q}\right) .
$$

\section{Simulation Analysis}

In the simulation model, the motor is a 8-pole, 36-slot surface-mounted PMSM, and its detailed parameters are shown in Table 1. In addition, the vector control method is adopted in the PMSM, where the $d$-axis current is equal to 0 .

4.1. Simulation Analysis of Inductance. According to equations (7)-(11), the simulation model of inductance estimation in MATLAB is established, as shown in Figure 4, where $k_{p}=0.002$ and $k_{i}=250$.

In order to verify the correctness of the PMSM model, several specific parameters of the PMSM in operation are solved by simulation, corresponding to the speed rises from $1000 \mathrm{r} / \mathrm{min}$ to $2000 \mathrm{r} / \mathrm{min}$ in one second. Figure 5 shows the simulation result of $d$-axis current under different rotational speeds, which is approximately equal to zero, and the result is consistent with the control strategy of $i_{d}=0$.

The estimated value of inductance is obtained by simulation, as shown in Figure 6. As the initial value of $L(0)$ differs from the actual value, it takes time to self-correct for the adaptive model. From Figure 6, it can be concluded that the estimated value is getting closer to the actual value $(2.94 \mathrm{mH})$, and it eventually stabilizes at this value. It can also be seen that the method has a fast response, and the inductance value can be estimated in a very short time.

At the same time, the difference of $d$-axis current between the reference model and adaptive model is obtained, as shown in Figure 7. As the difference approaches to 0, the 
TABLE 1: Detailed parameters of PMSM.

\begin{tabular}{lcc}
\hline Parameters & Name & Value \\
\hline Number of poles & $P$ & 8 \\
Stator resistance & $R$ & $1.01(\Omega)$ \\
Stator inductance & $L$ & $2.94(\mathrm{mH})$ \\
Rotor inertia & $J$ & $1.53 \times 10^{3}\left(\mathrm{~kg} / \mathrm{m}^{2}\right)$ \\
PM flux linkage & $\lambda_{m}$ & $0.147(\mathrm{~Wb})$ \\
\hline
\end{tabular}

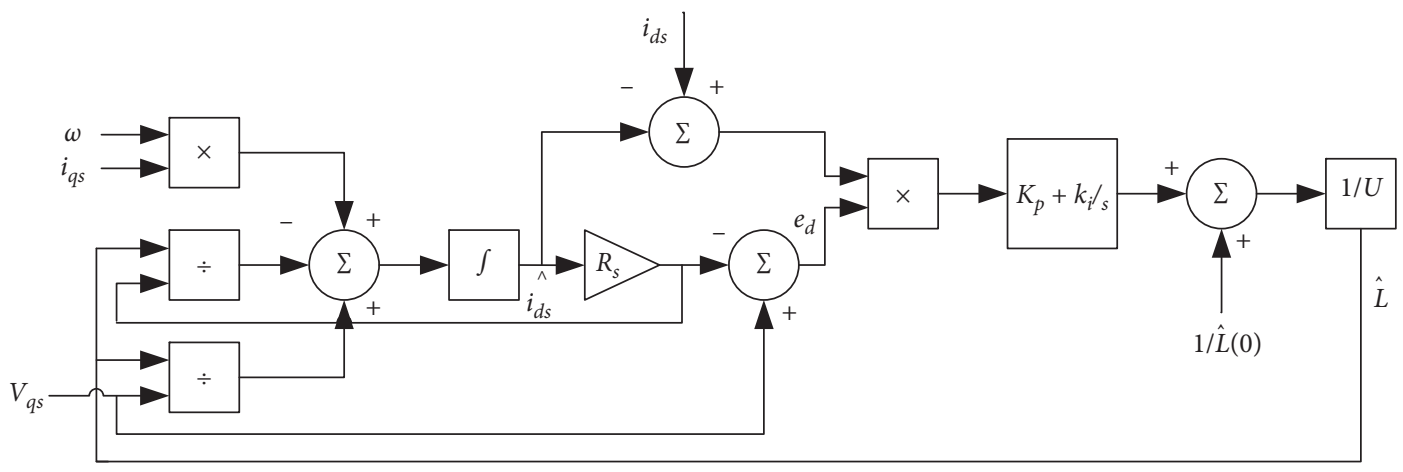

Figure 4: Simulation model of inductance estimation.

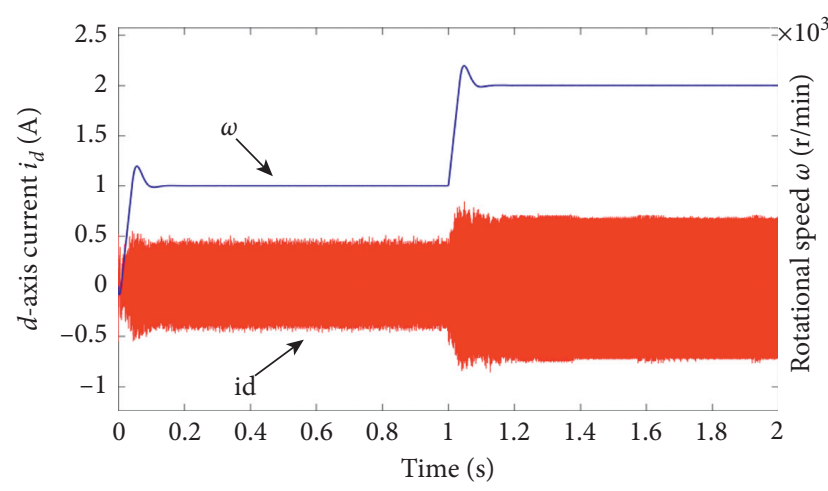

FIGURE 5: Simulation result of $d$-axis current $i_{d}$ under different rotational speeds $\omega$.

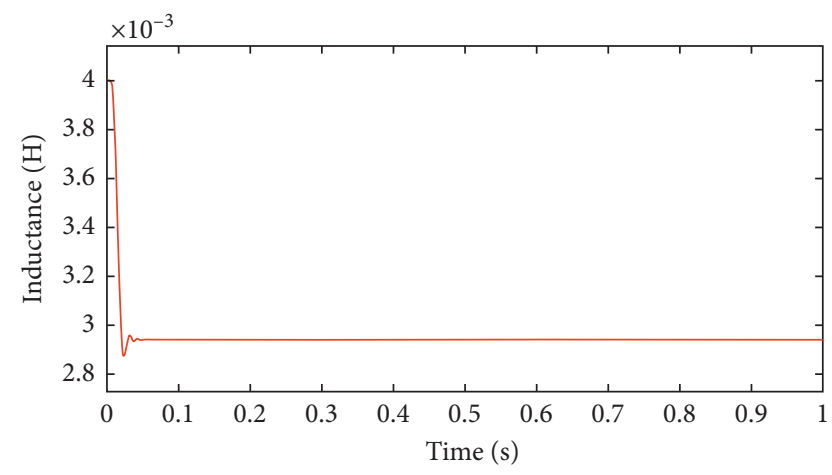

Figure 6: Curve of estimated inductance in simulation.

estimated $d$-axis current value is consistent with the actual $d$ axis current value. According to the definition of model reference adaptation system, the smaller the value of $e_{d}$, the smaller the difference between the output value and the ideal value.

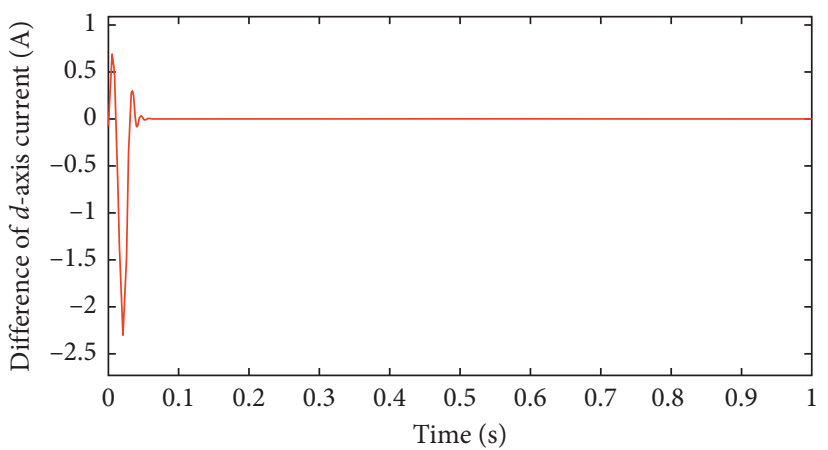

Figure 7: Curve of difference of $d$-axis current.

In order to verify the stability of the established model, the inductance parameters of the motor are changed to $2.5 \mathrm{mH}, 3 \mathrm{mH}$, and $3.5 \mathrm{mH}$, respectively. The curves of estimated inductance of the motor model with the same initial value are obtained, as shown in Figure 8. It can be seen that the inductance value tends to equal the set value, and the stability of the MRAS is well.

PMSM can work in a wide speed range due to its high speed characteristics, and it is difficult to apply the constant PI parameter at the full speed range; the fuzzy control is introduced to improve the deficiency and applicable speed range of MRAS. As shown in Figure 1, the fuzzy control unit is introduced into traditional MRAS, and the simulation model is named model reference fuzzy adaptive control (MRFAC) method.

In traditional MRAS with fuzzy control algorithm, the fuzzy control is connected with the PI controller, and the fuzzy controller is used to update the PI parameters according to the operation condition, and it requires extensive experience to determine the PI parameters of the motor at different operating stages. For the inductance 




Figure 8: Simulation curves under different inductances.

estimation model, the $d$-axis current error between the reference model and the adaptive model is used as the input and output for fuzzy control, that is, the $d$-axis current error is fuzzed, as shown in Figure 1.

Figure 1 shows the flowchart of MRFAC, where output $u$ is current error of $d$-axis and $\Delta e$ is the rate of change of $e$. The input scaling factor $K_{e}, K_{c}$, and output scaling factor $K_{u}$ of the fuzzy controller can be modified according to the actual situation.

Figure 9 shows the membership function of input $e, \Delta e$, and output $u$, where $\mathrm{NB}$ is negative big, $\mathrm{NM}$ is negative medium, NS is negative small, $\mathrm{ZE}$ is zero, PS is positive small, $\mathrm{PM}$ is positive medium, and $\mathrm{PB}$ is positive big.

The logic rules of fuzzy control for the inductance model are shown in Table 2.

In order to verify the stability of the system of the estimation model after adding fuzzy control algorithm, the curves of estimated inductance are simulated based on MRAS and MRFAC, as shown in Figure 10. It can be seen that the estimation results of the two methods are similar, and the estimated time for both is shorter, but the response speed of the MRFAC method is faster than that of the MRAS method.

In [23], the robustness of the estimated model was tested by changing the load torque of motor during the simulation process. In this paper, the same method is adopted to test the stability of the MRFAC system. Figure 11 shows the torque change during motor operation, and Figure 12 shows the estimated inductance value during this operation. It can be seen from Figure 12 that when the torque changes, the estimated inductance value almost does not change, and the estimation model can be considered stable.

4.2. Simulation Analysis of the Flux Linkage. According to equations (12)-(15), the simulation model of flux linkage estimation is established, as shown in Figure 13, where $k_{p}$ is equal to 0.00002 and $k_{i}$ is equal to 0.002 , and the previously

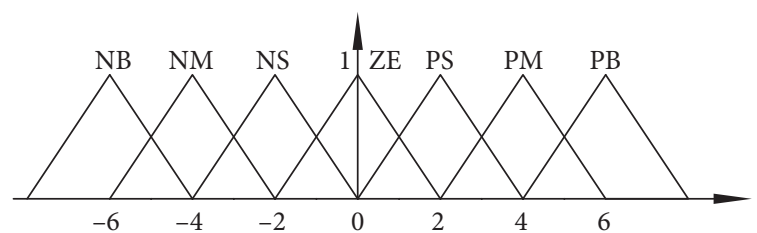

FIgURE 9: The membership function of input and output.

TABle 2: Logic rules of fuzzy control for the inductance model.

\begin{tabular}{lccccccc}
\hline$\Delta e l e$ & NB & NM & NS & ZE & PS & PM & PB \\
\hline NB & NB & NB & NM & NS & NS & NS & PM \\
NM & NB & NB & NM & NS & NS & ZE & PM \\
NS & NB & NM & MS & MS & ZE & PM & PM \\
ZE & NM & NM & NS & ZE & PS & PM & PB \\
PS & NM & NM & ZE & PS & PS & PM & PB \\
PM & NM & ZE & PS & PS & PM & PB & PB \\
PB & NM & PS & PS & PS & PM & PB & PB \\
\hline
\end{tabular}

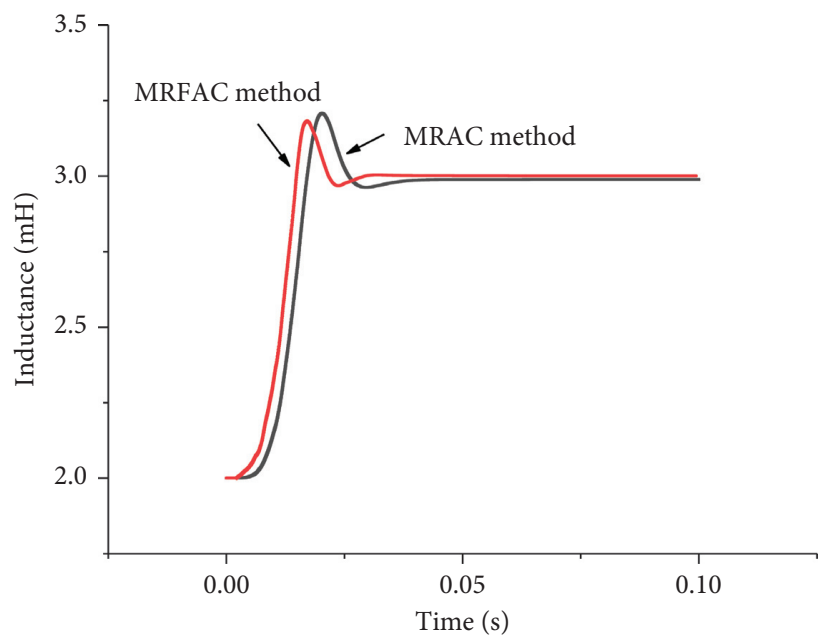

FIgURE 10: Estimated inductance based on MRAS and MRFAC.

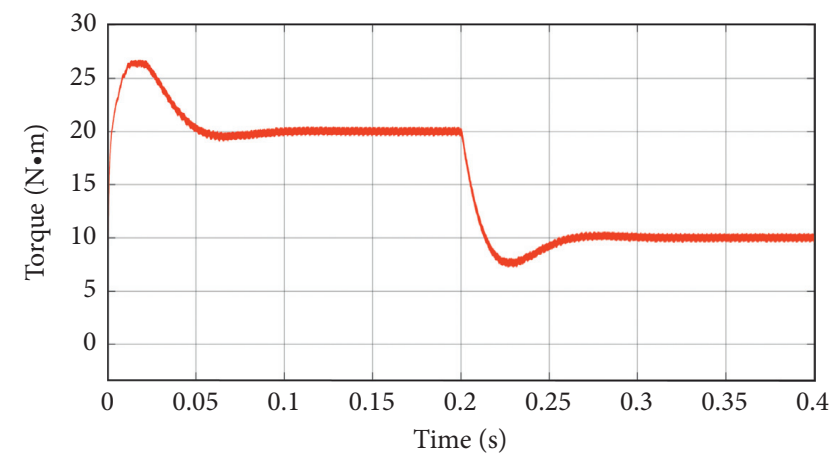

Figure 11: Variation of load torque.

estimated inductance values are used in the model for simulation.

In order to study the accuracy of the estimation model based on traditional MRAS, the flux linkage values are estimated at five different rotating speeds, respectively, as shown in Figure 14. As the PI parameter is set according to 


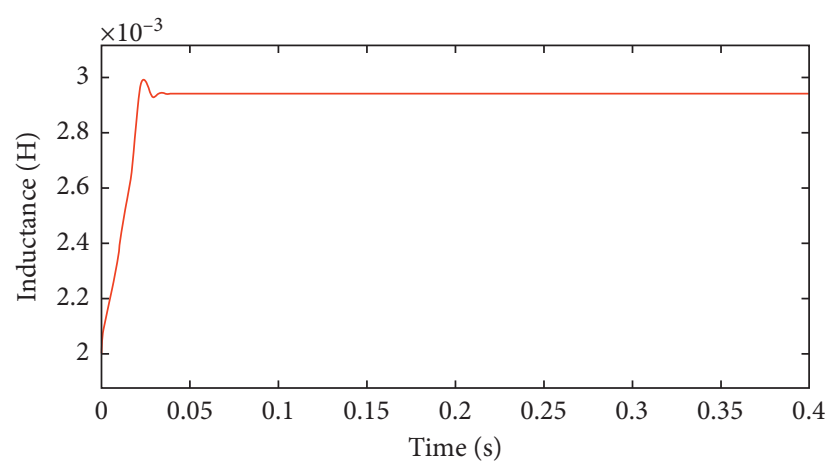

Figure 12: Inductance estimation under torque variation.

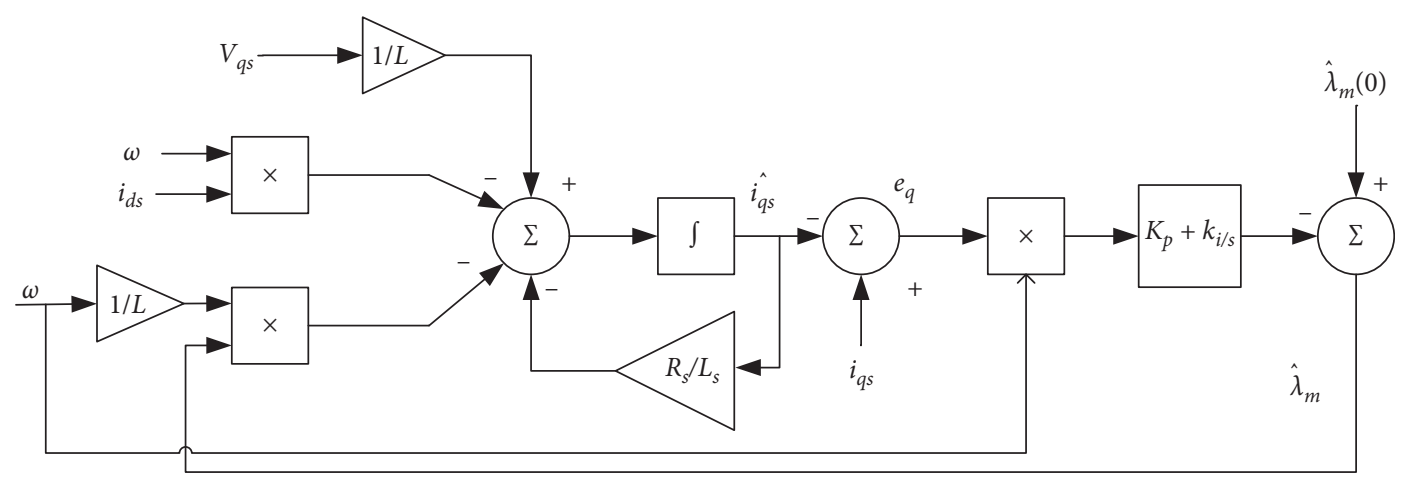

FIGURE 13: Simulation model of flux linkage estimation.

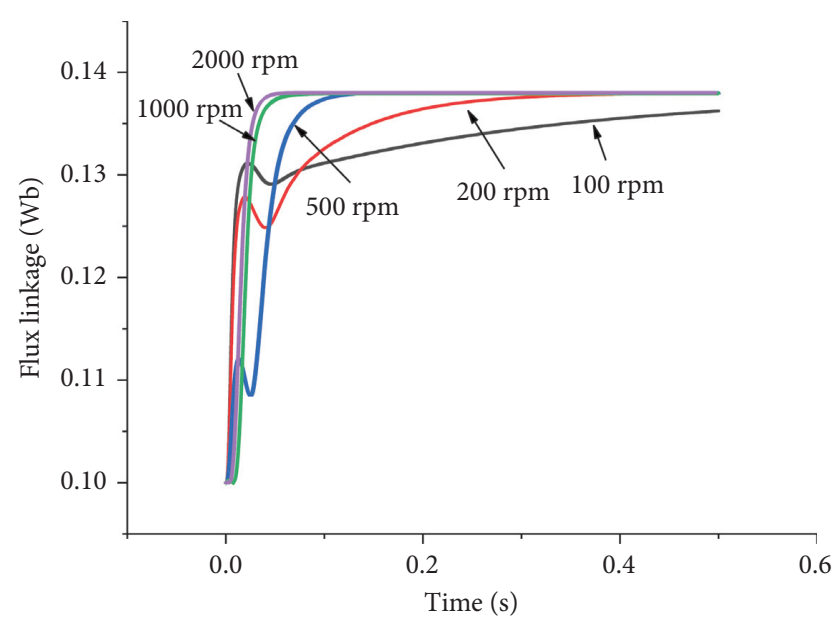

FIGURE 14: Estimated flux linkage based on traditional MRAS at different rotating speeds.

the rotating speed, the response speed and accuracy of the estimation result will decrease with the decrease of speed.

Fuzzy control algorithm is also introduced in MRAS, similar to the inductance estimation model. In this part, fuzzy control algorithm is used to replace the adaptive mechanism in traditional MRAS. Unlike the inductance estimation model, the input of the flux linkage estimation model has been changed from $e_{d}$ to $\omega \cdot e_{q}$, which leads to the change of fuzzy logic rules, as shown in Figure 2, where $K_{e}$, $K_{c}$, and $K_{u}$ are $6 / 1400,6 / 440000$, and 6, respectively.
The fuzzy control output is the flux linkage value, and the membership function remains unchanged. Table 3 gives the logic rules of fuzzy control for flux linkage.

Figure 15 shows the estimated flux linkage value in the varying speed process. The starting speed starts at low speed $(100 \mathrm{r} / \mathrm{min})$ and rises to high speed $(2500 \mathrm{r} / \mathrm{min})$ in 0.2 seconds. It can be seen that the introduction of fuzzy control in MRAS has a good adaptation to the varying speed process. In the low rotating speed stage, the flux linkage can be estimated quickly and accurately; at the same time, the estimated value almost does not fluctuate from low speed to high speed.

Because the stator resistance of the estimated model is measured by thermal resistance, the stator resistance value may fluctuate. Figure 16 shows the results of the flux linkage estimation in the case of stator resistance fluctuations; the fluctuation occurs at 0.2 seconds and then returns to initial values. It can be seen from the figure that the fluctuation will cause an error in the estimation result, but the estimated value will return to the correct value when the fluctuation disappears, and this also proves the stability of the system.

4.3. Detection of Winding Resistance. The input of the proposed model is $U_{d q}, i_{d q}, \omega$, and $R$. $U_{d q}, i_{d q}$, and $\omega$ can be obtained by direct measurement. As the stator winding resistance is obviously affected by temperature change, its value can be calculated based on the measured temperature according to equation (6). As shown in Figure 17(a), four thermal resistors are placed in four different positions in the 
TABLe 3: Logic rules of fuzzy control for flux linkage.

\begin{tabular}{llllccc}
\hline$\Delta e l e$ & NB & NM & NS & ZE & PS & PM \\
\hline NB & PB & PB & PM & PM & NB & PS \\
NM & PB & PB & PM & PS & ZE & ZE \\
NS & PM & PM & ZE & NS \\
ZE & PM & PM & IS & ZE & NE \\
PS & PM & PS & NS & NM & NB \\
PM & PS & ZE & NS & NS & NB & NB \\
PB & ZE & NS & NM & NM & NB & NB \\
\hline
\end{tabular}

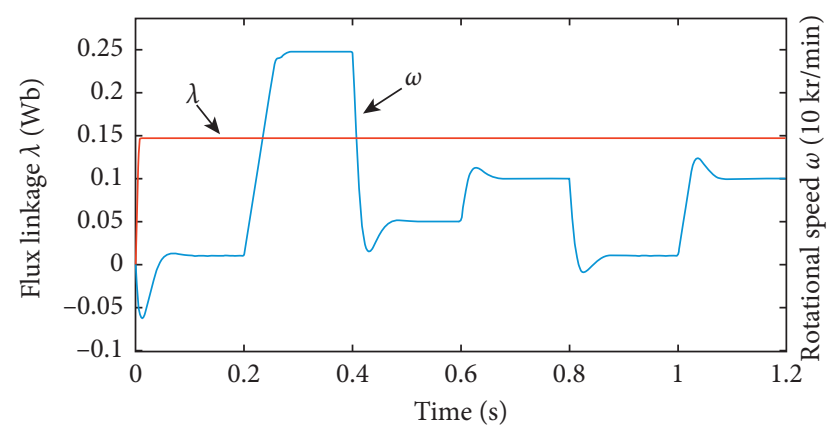

FIgURE 15: Curve of estimated flux linkage.

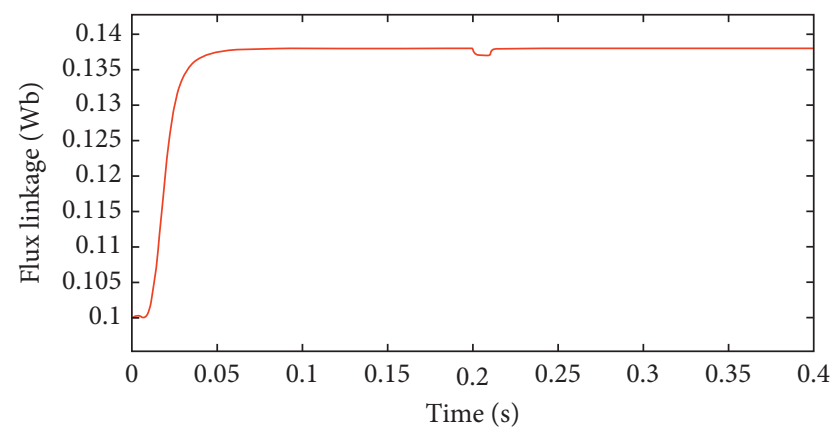

FIGURE 16: Flux linkage estimation in case of stator resistance fluctuation.

motor windings, and Figure 17(b) shows the average temperature of the four temperature measuring points in 150 minutes.

Figure 18 shows the relationship between the rotor flux linkage and its temperature. The measured winding resistance is substituted into the simulation model based on MRFAC to estimate the inductance and flux linkage, which are the real-time values corresponding to working temperature. Then, the estimated flux linkage value and the flux linkage value at room temperature are substituted into equation (5), and the rotor temperature can be obtained.

\section{Experiment}

In the experiment, the BEMF of PMSM is measured, which is used to calculate the BEMF coefficient (flux linkage), by equation (16). And the value of flux linkage measured is compared with the estimated value, which is used to verify the effectiveness of the proposed method. The BEMF coefficient can be expressed as

$$
K_{e}=\frac{U}{(2 \pi / 60) n p_{\text {pole }}},
$$

where $K_{e}$ denotes BEMF coefficient, which equals the flux linkage of PMs in rotor, $U$ is the amplitude of phase BEMF, $n$ is the measured speed of PMSM, and $p_{\text {pole }}$ is the number of pole pairs.

The experimental testing equipment is shown in Figure 19, where the initial motor temperature (room temperature) is $25^{\circ} \mathrm{C}$. Two identical motors are connected by a coupling: one motor is an experimental motor (motor mode) and the other is the load motor (generator mode). When the winding temperature reaches a certain temperature, the load motor drives the experimental motor running, and the BEMF of the experimental motor is measured by oscilloscope without eliminating the load voltage and harmonics. Then, the BEMFs are substituted into equation (16) to obtain the flux linkage.

When the winding temperature reaches $30^{\circ} \mathrm{C}, 35^{\circ} \mathrm{C}, 40^{\circ} \mathrm{C}$, $45^{\circ} \mathrm{C}$, and $47.5^{\circ} \mathrm{C}$ (thermal steady state), the BEMF of the experimental motor is measured. Then, the BEMF is converted to flux linkage value according to equation (16), and the flux linkage is solved under different temperatures. At the same time, the stator resistance value corresponding to this temperature point is substituted into the estimation model, and the flux linkage is estimated based on the MRFAC method for obtaining the PM temperature.

Table 4 gives the flux linkage values measured and estimated at different winding temperature points, and the value in parentheses is the temperature corresponding to the flux linkage value. It can be seen that the estimated error does not exceed $3^{\circ} \mathrm{C}$, which proves the validity of the proposed estimation method.

Table 5 shows the comparison between the proposed method in this paper and other methods. It can be seen that the BEMF method has the smallest error, but it needs to perform Fourier operation on the BEMF and analyse the harmonics, so the solution process is complex. The flux observer method has the largest error among the three methods, and its input can be directly measured and its response is fast, which is suitable for real-time temperature estimation. The proposed method can estimate flux linkage quickly based on the variation of stator resistance corresponding to different working temperatures measured by thermal resistance, and the PM temperature will be obtained according to the estimated permanent magnet flux linkage. MRAS and fuzzy control are stable and mature control 


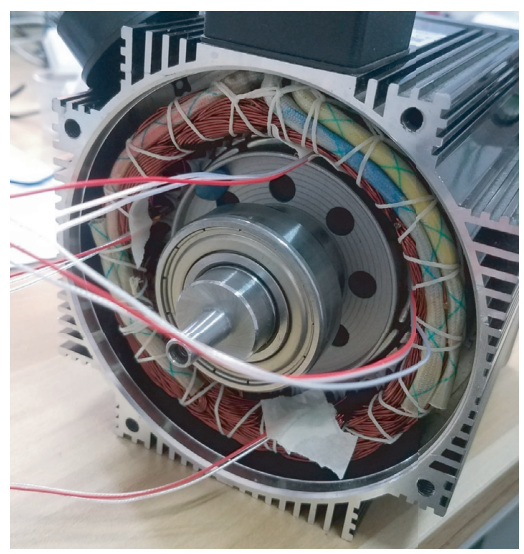

(a)

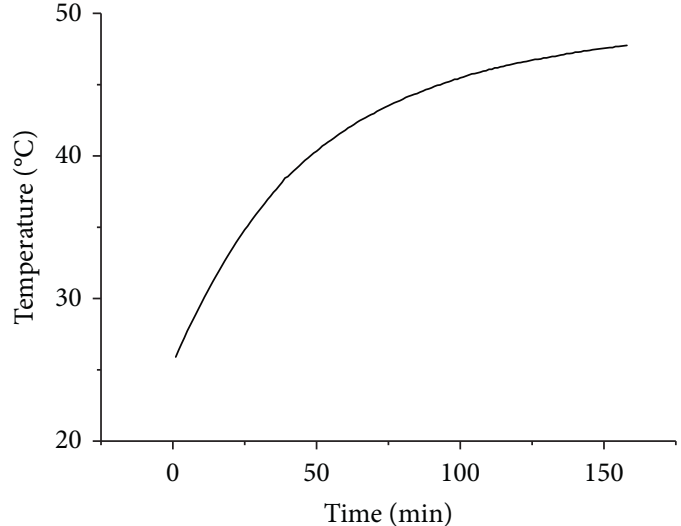

(b)

FIgURE 17: Winding temperature measurement experiment. (a) Installation position of thermal resistance. (b) Curve of winding temperature rise.

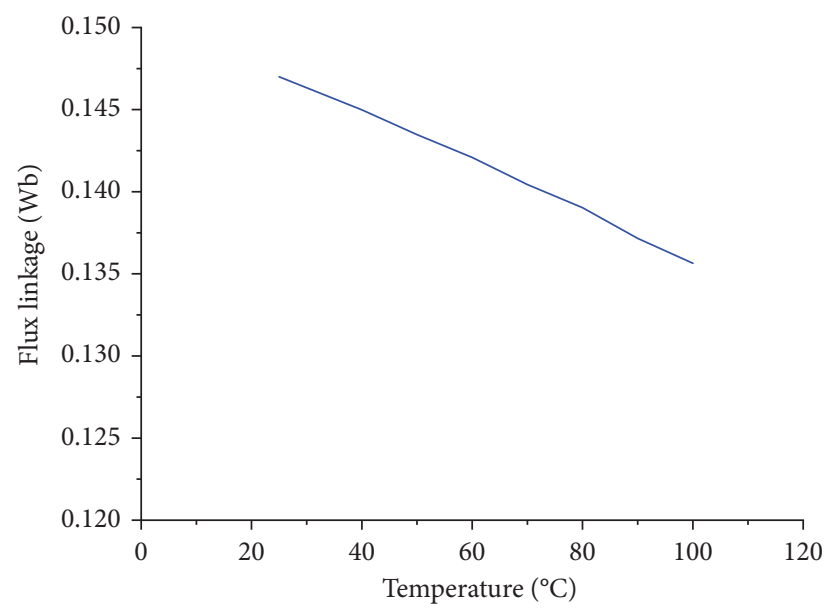

FIgURE 18: The relation curve between temperature and flux linkage.

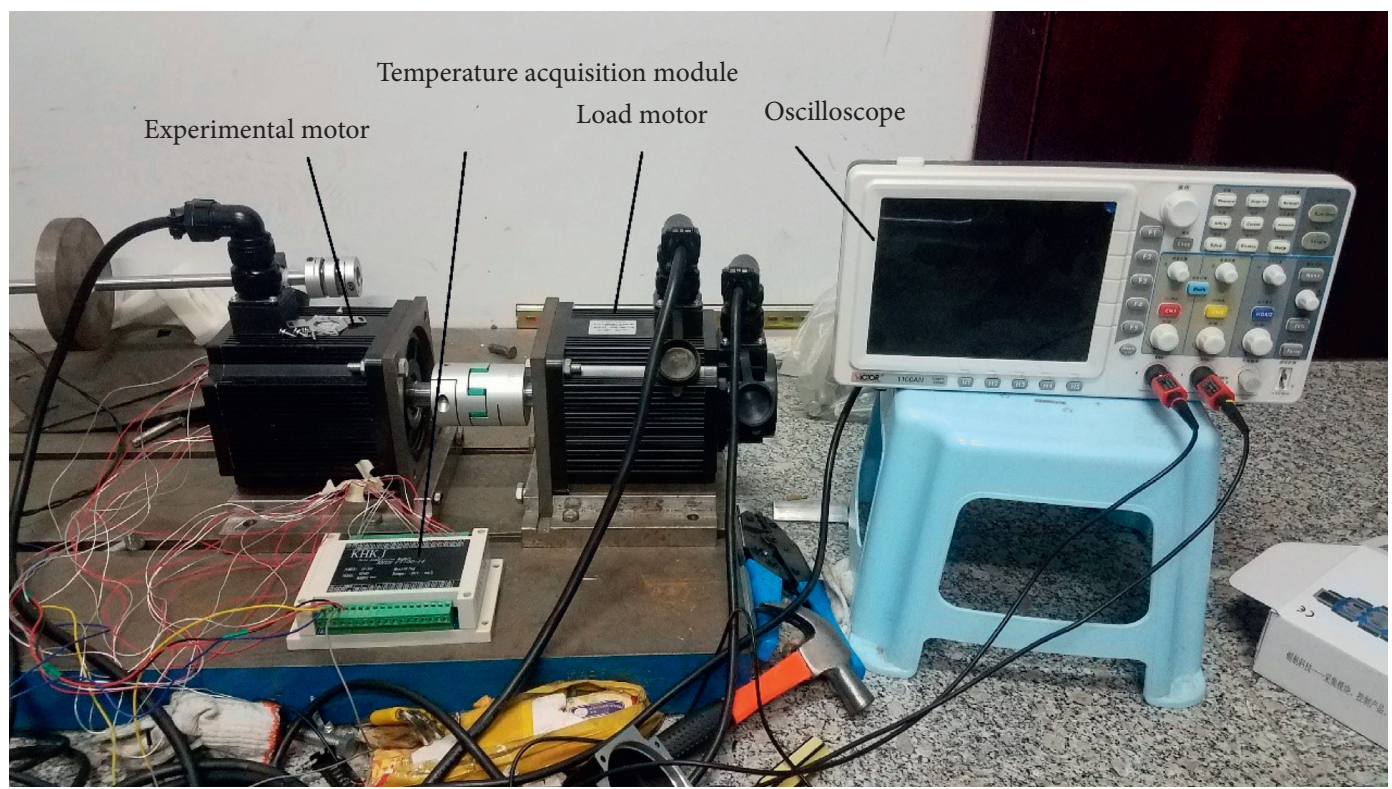

FIGURE 19: Experimental testing equipment. 
TABLE 4: Flux linkage values measured and estimated.

\begin{tabular}{lcc}
\hline Winding temperature $\left({ }^{\circ} \mathrm{C}\right)$ & Flux linkage value/Wb (measured) & Flux linkage value/Wb (estimated) \\
\hline 25 & $0.147\left(25^{\circ} \mathrm{C}\right)$ & $0.147\left(25^{\circ} \mathrm{C}\right)$ \\
30 & $0.1458\left(34.87^{\circ} \mathrm{C}\right)$ & $0.146\left(33.22^{\circ} \mathrm{C}\right)$ \\
35 & $0.145\left(39.9^{\circ} \mathrm{C}\right)$ & $0.1449\left(40.65^{\circ} \mathrm{C}\right)$ \\
40 & $0.1442\left(44.88^{\circ} \mathrm{C}\right)$ & $0.1439\left(47.01^{\circ} \mathrm{C}\right)$ \\
45 & $0.1432\left(52.1^{\circ} \mathrm{C}\right)$ & $0.1429\left(54.24^{\circ} \mathrm{C}\right)$ \\
47.5 & $0.1423\left(58.5^{\circ} \mathrm{C}\right)$ & $0.1424\left(57.8^{\circ} \mathrm{C}\right)$ \\
\hline
\end{tabular}

TABle 5: Comparison of different methods.

\begin{tabular}{lcc}
\hline Method & Method of obtaining flux linkage & Max error $\left({ }^{\circ} \mathrm{C}\right)$ \\
\hline Proposed method & MRFAC & 3 \\
BEMF method [4] & Harmonic analysis of back EMF & 2 \\
Flux observer method [16] & Flux observer & 5 \\
\hline
\end{tabular}

strategies; the maximum error of estimated results is $3^{\circ} \mathrm{C}$, which is within the acceptable range.

\section{Conclusions}

The temperature rise will cause the demagnetization of PMs, which will affect adversely the efficiency of the PMSM, and it is very important to detect the temperature of PMs in rotor to ensure the efficient and safe operation of the motor. Due to the limitations of traditional temperature measurement methods, a new temperature estimation method using model reference fuzzy adaptive control (MRFAC) is proposed to estimate PM temperature, which relies on the linear relationship between flux linkage and temperature. In the new method, the MRAS parameter estimation method is adopted to estimate the flux linkage to obtain the rotor temperature, and in order to improve the accuracy and applicable speed range of the estimation model, a fuzzy control method is introduced to MRAS. Compared with the experimental data, the estimated temperature of PMs in rotor is very close to the experimental actual value. Also, this method can greatly simplify the rotor temperature measurement; it is suitable for temperature estimation of PMs in rotor of PMSM.

\section{Data Availability}

The data used to support the findings of this study are available from the corresponding author upon request.

\section{Conflicts of Interest}

The authors declare no conflicts of interest, financial or otherwise.

\section{Acknowledgments}

This research was supported by the Key Research and Development Project of Shandong Province (2017GGX203005) and Natural Science Foundation Project of Shandong Province (ZR2019MEE068).

\section{References}

[1] W. Fengxiang, Study on Design Feature and Related Technology of High Speed Electrical Machines, Journal of Shenyang University of Technology, Shenyang, China, 2006.

[2] F. Wang, M. Zong, W. Zheng, and E. Guan, "Design features of high speed PM machines," in Proceedings of the 6th International Conference on Electrical Machines and Systems, vol. 1, pp. 66-70, Beijing, China, November 2003.

[3] D. Fernandez, D. Hyun, Y. Park et al., "Permanent magnet temperature estimation in pm synchronous motors using low cost hall effect sensors," in Proceedings of the 2016 IEEE Energy Conversion Congress and Exposition (ECCE), vol. 9, Milwaukee, WI, USA, September 2016.

[4] D. D. Reigosa, D. Fernandez, T. Tanimoto, T. Kato, and F. Briz, "Permanent-magnet temperature distribution estimation in permanent-magnet synchronous machines using back electromotive force harmonics," IEEE Transactions on Industry Applications, vol. 52, no. 4, pp. 3093-3103, 2016.

[5] D. D. Reigosa, F. Briz, P. García, J. M. Guerrero, and M. W. Degner, "Magnet temperature estimation in surface PM machines using high-frequency signal injection," IEEE Transactions on Industry Applications, vol. 46, no. 4, pp. 1468-1475, 2010.

[6] D. Reigosa, F. Briz, M. W. Degner, P. Garcia, and J. M. Guerrero, "Magnet temperature estimation in surface PM machines during six-step operation," IEEE Transactions on Industry Applications, vol. 48, no. 6, pp. 2353-2361, 2012.

[7] D. Reigosa, D. Fernandez, H. Yoshida, T. Kato, and F. Briz, "Permanent magnet temperature estimation in PMSMs using pulsating high frequency current injection," in Proceedings of the IEEE Energy Conversion Congress and Exposition (ECCE), vol. 51, pp. 3159-3168, Pittsburgh, PA, USA, Sepetmber 2014.

[8] D. Fernandez, D. Reigosa, T. Tanimoto, T. Kato, and F. Briz, "Wireless permanent magnet temperature and field distribution measurement system for IPMSMs," in Proceedings of the 2015 IEEE Energy Conversion Congress and Exposition (ECCE), vol. 10, pp. 3996-4003, Montreal, Canada, September 2015.

[9] M. Ganchev, C. Kral, and T. M. Wolbank, "Compensation of speed dependency in sensorless rotor temperature estimation for permanent magnet synchronous motor," in Proceedings of the International Conference on Electrical Machines (ICEM), vol. 11, pp. 1612-1618, Marseille, France, September 2012. 
[10] M. Ganchev, C. Kral, and H. Oberguggenberger, "Sensorless rotor temperature estimation of permanent magnet synchronous motor under load conditions," in Proceedings of the IECON 2012-38th Annual Conference on IEEE Industrial Electronics Society, vol. 12, pp. 84-91, Montreal, Canada, October 2012.

[11] Y. Jiang, D. Wang, J. Chen, Q. Zhang, and T. Xuan, "Electromagnetic-thermal-fluidic analysis of permanent magnet synchronous machine by bidirectional method," IEEE Transactions on Magnetics, vol. 54, no. 3, pp. 1-5, 2018.

[12] D. Reigosa, D. Fernandez, T. Tanimoto, T. Kato, and F. Briz, "Comparative analysis of BEMF and pulsating high frequency current injection methods for PM temperature estimation in PMSMs," IEEE Transactions on Power Electronics, vol. 32, no. 5, pp. 3691-3699, 2017.

[13] A. J. Grobler, S. R. Holm, and G. V. Schoor, "Thermal modelling of a high speed permanent magnet synchronous machine," in Proceedings of the International Electric Machines \& Drives Conference, vol. 7, pp. 319-324, Chicago, IL, USA, May 2013.

[14] H. Li and Y. Shen, "Thermal analysis of the permanentmagnet spherical motor," IEEE Transactions on Energy Conversion, vol. 30, no. 3, pp. 991-998, 2015.

[15] A. Boglietti, A. Cavagnino, D. Staton, M. Shanel, M. Mueller, and C. Mejuto, "Evolution and modern approaches for thermal analysis of electrical machines," IEEE Transactions on Industrial Electronics, vol. 56, no. 3, pp. 871-882, 2009.

[16] A. Swanson, "Determination of rotor temperature for an interior permanent magnet synchronous machine using a precise flux observer," in Proceedings of the 2014 International Power Electronics Conference, vol. 8, Hiroshima, Japan, May 2014.

[17] K. Liu and Z. Q. Zhu, "Mechanical parameter estimation of permanent magnet synchronous machines with aiding from estimation of rotor PM flux linkage," in Proceedings of the 2014 IEEE Energy Conversion Congress and Exposition (ECCE), pp. 3115-3125, Pittsburgh, PA, USA, September 2014.

[18] L. Jilong, X. Fei, and S. Yang, "Positionsensorless control technology of permanent-magnet synchronous motor-a review," Transactions of China Electrotechnical Society, vol. 32, no. 16, pp. 76-88, 2017.

[19] A. Khlaief, M. Boussak, and A. Châari, "A MRAS-based stator resistance and speed estimation for sensorless vector controlled IPMSM drive," Electric Power Systems Research, vol. 108, no. 3, pp. 1-15, 2014.

[20] X. Liu, G. Zhang, L. Mei, D. Wang, and C. Sciences, "Backstepping control with speed estimation of PMSM based on MRAS," Automatic Control and Computer Sciences, vol. 50, no. 2, pp. 116-123, 2016.

[21] H. Chen and N. Sun, "Nonlinear control of underactuated systems subject to both actuated and unactuated state constraints with experimental verification," IEEE Transactions on Industrial Electronics, 2019.

[22] H. Chen, B. Xuan, P. Yang, and H. Chen, "A new overhead crane emergency braking method with theoretical analysis and experimental verification," Nonlinear Dynamics, vol. 98, no. 3, pp. 2211-2225, 2019.

[23] Z. Boulghasoul, A. Elbacha, E. Elwarraki, and D. Yousfi, "Robustness of fuzzy controller based adaptation mechanism for MRAS sensorless IM drives," in Proceedings of the 19th International Conference on Electrical Machines IEEE, vol. 10, Rome, Italy, September 2010.
[24] S. Fan, W. Luo, J. Zou, and G. Zheng, "A hybrid speed sensorless control strategy for PMSM Based on MRAS and Fuzzy control," in Proceedings of the 7th International Power Electronics and Motion Control Conference, Harbin, China, June 2012.

[25] D.-M. Lee, "On-line parameter identification of SPM motors based on MRAS technique," International Journal of Electronics, vol. 104, no. 4, pp. 593-607, 2016.

[26] J.-S. Ko, J.-H. Huh, and J.-C. Kim, "Improvement of temperature control performance of thermoelectric dehumidifier used industry 4.0 by the SF-PI controller," Processes, vol. 7, no. 2, p. 98, 2019. 